\title{
Educação popular no Rio Grande do Norte: A Campanha "de pé no chão também se aprende a ler"
}

\author{
Marlúcia Menezes de Paiva *
}

Resumo. O período de vigência democrática no Brasil, de 1945 a 1964, provocou a organização da sociedade civil e a consequente realização de medidas populares. Uma dessas realizações foi uma experiência em educação popular desenvolvida pela Prefeitura de Natal, na administração do governador Djalma Maranhão (1960-1964). A experiência recebeu o nome de Campanha "de pé no chão também se aprende a ler", foi destinada às populações pobres da cidade, desenvolveu uma alfabetização que era também conscientizadora. As escolas, chamadas de "Acampamentos", por falta de recursos, foram construídas com palha de coqueiro. As professoras foram formadas, grande parte, em cursos emergenciais, mas também na Escola Normal. Foi uma experiência exitosa, que atendeu aos anseios das populações carentes. 0 golpe de Estado de 1964, que reprimiu violentamente essa experiência, prendendo, torturando seus executores, pôs fim a essa experiência.

Palavras chave: Educação popular; educação de adultos; Campanha "de pé no chão também se aprende a ler".

EDUCACIÓN POPULAR EN RIO GRANDE DEL NORTE: LA CAMPAÑA "DE PIE EN EL SUELO TAMBIÉN SE APRENDE A LEER"

Resumen. El período del régimen democrático en Brasil, de 1945 a 1964, condujo a la organización de la sociedad civil y la consecuente realización de medidas populares. Uno de esos logros fue una experiencia en educación popular desarrollada por el Ayuntamiento de Natal, en la administración del gobernador Djalma Maranhão (1960-1964). La experiencia fue nombrada Campaña "de pie en el suelo también se aprende a leer", y estuvo destinada a la gente pobre de la ciudad. Desarrolló una alfabetización que también era la conciencia crítica. Las escuelas, denominadas "Campamentos" debido a la falta de recursos, fueron construidas con paja de cocotero. Los cursos de formación para gran parte de las profesoras fueron los cursos de emergencia, pero también en la Escuela Normal. Ha sido una experiencia de gran éxito, que respondió a los anhelos de las personas necesitadas. El golpe de Estado de 1964, que reprimió violentamente esa experiencia, deteniendo y torturando a sus ejecutores, puso fin a esa experiencia.

Palabras clave: Educación popular; educación para adultos; Campaña "de pie en el suelo también se aprende a leer".

\footnotetext{
* Universidade Federal do Rio Grande do Norte (UFRN), Brasil
} 
POPUlaR EDUCATION IN RIO GRANDE DO NORTE: THE CAMPAigN "STANDING ON THE GROUND ALSO LEARNS TO READ"

Abstract. The period covered in Brazil, democratic of 1945 to 1964, triggered the civil society organisation and the consequent realization of popular measures. One of those achievements was an experiment in popular education developed by the city of Natal, in the administration of Governor Djalma Maranhão (1960-1964). The experience was "de pé no chão também se aprende a ler", was aimed at the poor of the city, developed a literacy that was also fitness. The schools, called "camps", for lack of resources, were built with coconut husks. The teachers were formed, to a large extent in emergency courses, but also courses in Normal School. It was a successful experience, who answered the wishes of needy populations. The 1964 coup $d$ 'état, which repressed violently that experience, arresting, torturing their executors, put an end to this experience.

Keywords: Popular education; Adult education; Djalma Maranhão.

\section{INTRODUÇÃO}

No Brasil, a vigência do estado democrático, no período de 1945 a 1964, teve como uma de suas consequências o crescimento e organização da sociedade civil, ocasionando a mobilização de setores em prol de reformas estruturais para o país, as denominadas reformas de base, necessárias ao desenvolvimento econômico, social.

No âmbito da sociedade civil, laica, facções políticas, progressistas e nacionalistas, eleitas nesse processo democrático em expansão, favoreceram o surgimento de movimentos de educação e cultura popular. Em Natal, por exemplo, em 1961, surgiu um movimento de educação popular, de responsabilidade da Prefeitura Municipal de Natal, que tendo à frente o governo democrático-popular de Djalma Maranhão, instituiu a denominada "Campanha de pé no chão também se aprende a ler" e significou uma experiência inovadora na educação, com grande participação popular, voltado para as camadas mais pobres da população da cidade do Natal.

Anteriormente, em 1958, a Arquidiocese de Natal e setores progressistas da Ação Católica haviam criado uma experiência em educação popular utilizando o rádio, quer dizer, um início de educação à distância, embora mediada por um monitor. Essa educação que teve como público alvo prioritário as populações rurais, foi denominada de Escolas Radiofônicas. Posteriormente, a expansão dessas escolas fez surgir o Movimento de Educação de Base (MEB), que extrapolou os limites do Estado do Rio Grande do Norte, atingindo regiões mais pobres do país, com altos índices de analfabetismo, que à época atingia percentuais de até $70 \%$. 
Essas duas experiências alcançaram um contingente expressivo da população, desenvolvendo, além da alfabetização, uma ação pedagógica conscientizadora. Pouco tempo depois, em 1963, ocorreu na cidade de Angicos, município do sertão norte-rio-grandense, promovida pelo Governo do Estado, uma experiência em educação popular conhecida como "As 40 horas de Angicos".

Nessa cidade, o educador Paulo Freire aplicou em escala maior, pela primeira vez, o seu sistema educacional. Até então, o sistema estava pensado e aplicado em pequenos grupos, na cidade do Recife/PE, no âmbito das políticas desenvolvidas pelos governos estadual de Miguel Arrais e municipal de Pelópidas da Silveira. Ambos compunham uma frente política progressista, da qual fazia parte o então prefeito de Natal, Djalma Maranhão. Naquele momento, ao aplicá-lo em escala maior, o educador conseguiu consolidá-lo, redimensionando-o e adequando-o às necessidades da alfabetização das camadas mais pobres da população. Essas experiências perderam, com 0 Golpe de Estado de 1964, sua pujança, pois foram duramente reprimidas. O novo governo impôs uma nova-velha ordem.

Nesta pesquisa, trabalhamos com o movimento da Campanha "de pé no chão também se aprende a ler". Delimitamos nosso estudo a esse movimento educacional, na tentativa de recuperar nossa memória histórica, particularmente no campo da História da Educação, pois foi uma experiência educacional extinta com o golpe de Estado de 1964, e, por isso, temos dificuldade em encontrar dados que nos dê respaldo a sua reconstituição. Pouco registro é encontrado atualmente, pois a repressão a esse Movimento foi violenta e, como diz Jacques Le Goff (1996, p.426)

Do mesmo modo, a memória coletiva foi posta em jogo de forma importante nas lutas das forças sociais pelo poder. Tornarem-se senhores da memória e do esquecimento é uma das grandes preocupações das classes, dos grupos, dos indivíduos que dominaram e dominam as sociedades históricas. Os esquecimentos e os silêncios da história são reveladores desses mecanismos de manipulação da memória coletiva.

No movimento escolhido, optamos, como objeto de estudo, trabalhar o processo de formação dos professores, os materiais instrucionais de leitura utilizados na alfabetização, observando o livro, cartilha, entre outros materiais pedagógicos, destacando, também, os conteúdos ditos conscientizadores transmitidos nas diversas atividades de leitura, sem esquecer que, para as camadas mais pobres, a escola foi, ou talvez seja ainda, o único espaço de leitura. 0 estudo tem como limite o período do pós-guerra até 1964, ano em que ocorreu o golpe de Estado civil-militar, pois esse movimento educacional 
foi desbaratado, como dissemos antes, perdendo toda a pujança, ou mesmo sendo extintos, como foi o caso da Campanha "de pé no chão também se aprende a ler".

Os movimentos de educação e cultura popular das décadas 1950/1960, segundo Germano (2004) apresentam traços típicos do romantismo político: "recusa da realidade social presente, sensação de perda, nostalgia e busca do que foi perdido. Dessa forma, o presente seria negado e o futuro seria objeto de interrogação, tendo, de alguma maneira, uma referência ao passado." (2004, p.5). Em geral, os textos das lições dos livros de leitura estão impregnados desse espírito romântico, quase heroico.

Na Campanha "de pé no chão também se aprende a ler" observamos as "afinidades românticas da educação popular", expostas por Germano (2004). Mas, apesar desse particular, esse experimento educacional foi de grande importância nas lutas dos trabalhadores, no fazer valer os seus direitos e também de alfabetizá-los.

\section{A CAMPANHA “DE PÉ NO CHÃO TAMBÉM SE APRENDE A LER"}

Esse experimento educacional nasceu das lutas populares por mais educação. O primeiro prefeito eleito de Natal, em 1960, Djalma Maranhão, político, antes, membro dos quadros do Partido Comunista, elegera-se à frente de uma coligação de oposição, sustentada principalmente pela participação popular, constituída em Comandos Populares, composta por políticos, intelectuais, sindicalistas, estudantes, líderes de bairros. Esses Comandos prepararam a campanha do prefeito e criaram outras instâncias de organização, como os Acampamentos Nacionalistas, que serviam de orientação para os eleitores e também para arrecadar fundos para a campanha. A mais representativa das organizações, foram os chamados Comitês Nacionalistas, que arregimentaram pessoas por ruas e por bairros, criando uma rede capilar que conseguiu mobilizar politicamente toda a cidade do Natal. (Germano, 1982)

Após a posse, o prefeito cumprindo os compromissos da campanha e acatando reivindicações populares, particularmente dos 240 Comitês Nacionalistas, elegeu a educação e a cultura como prioridade de seu governo. 0 sistema educacional público estava em franca decadência. Faltavam escolas. O número de escolas públicas havia diminuído nos últimos anos. Entretanto, por falta de recursos, o prefeito enfrentou dificuldades para implantar reformas e melhorar a educação, como, por exemplo, construir novas escolas sem recursos para isso. O Governo Maranhão fazia oposição ao Governo Federal, sofrendo represálias por essa postura, uma delas era a falta de recursos. 
No início da administração, para iniciar a Campanha de Alfabetização, a prefeitura expandiu as denominadas escolinhas, classes de alfabetização, em sistema emergencial, quando foram utilizadas todas as salas disponíveis, cedidas pela comunidade, onde pudesse funcionar uma classe de alfabetização: sindicatos, igrejas, clubes, residências particulares e até um cinema. 0 material didático e a merenda eram doados aos alunos pelos poderes públicos, a professora, capacitada em cursos emergenciais, recebia um pequeno pró-labore, mas água e energia elétrica ficavam sob a responsabilidade das entidades responsáveis pela cessão da sala. Em dois anos, essas escolinhas haviam atingido o número de 271 salas de aula, entretanto, esse contingente não era suficiente para atender a demanda por alfabetização. Foi quando, das discussões e debates no Comitê Nacionalista do bairro das Rocas ${ }^{1}$, surgiu a ideia da construção de escolas utilizando-se as palhas de coqueiros. Moacyr de Góes, então Secretário de Educação do município, no seu livro "De Pé no Chão também se aprende a ler (1961-1964): uma escola democrática", relata esse momento do nascimento da Campanha:

A discussão foi longa. Por mais de duas horas ficamos em torno das mesmas questões: era preciso acabar com o analfabetismo - o povo queria, o prefeito também. Mas como acabar com o analfabetismo sem dinheiro para construir escolas? Não sei, realmente, de quem veio a proposta, naquela reunião de 40 a 50 homens e mulheres: - Faça uma escola de palha! (1980, p. 35)

Ao final da reunião a proposta foi levada ao prefeito que a aprovou. Tem início, então, o movimento educacional que recebeu o nome de "Campanha de pé no chão também se aprende a ler", nome retirado de um artigo de jornal escrito sobre o movimento educacional da prefeitura do Natal. A execução das medidas necessárias ao seu desenvolvimento ficou sob a responsabilidade da Secretaria de Educação, Cultura e Saúde, do Município, que, para esse fim, criou o Grupo de Trabalho de Educação Popular. 0 bairro das Rocas foi então selecionado para área-piloto da experiência e construção da primeira escola de palha. O Comitê Nacionalista daquele bairro era um dos mais importantes partícipes nas lutas e reivindicações populares.

A primeira escola construída recebeu o nome de Acampamento Escolar das Rocas e no mesmo ano, em 1961, a prefeitura construiu outro Acampamento Escolar no bairro do Carrasco. Logo foi feito a Chamada Escolar com a admissão dos alunos para dar início às aulas. Em 1962, foram construídos mais sete Acampamentos nos bairros Nordeste, Igapó, Aparecida, Quintas, Conceição, Granja e Nova Descoberta. É importante destacar, que todos eram bairros situados na periferia da cidade do Natal. Foram escolas

1 Rocas é um bairro da cidade do Natal habitado por camadas populares, de baixo poder aquisitivo. 
construídas para as camadas pobres da população. A matrícula evoluiu rapidamente, em 1960, as "Escolinhas" atendiam a 2.974 alunos; em 1961, o total de alunos atendido foi de 5.249. Quanto à matrícula das Escolas/ Acampamentos, segundo Germano (1982), é difícil de computar pela falta de registro. Goés, afirma que em abril de 1964, a matrícula geral excedia os 17.000 alunos. (1980, p. 79)

Os Acampamentos apresentavam uma arquitetura diferente das escolas tradicionais. Eram compostos por alguns galpões retangulares, onde funcionavam as salas de aula, de 30 X 8 metros, com cobertura de palha e chão de barro batido, sem paredes laterais; um galpão circular, com as mesmas características do anterior, destinado à recreação dos alunos, às festas e apresentações folclóricas e, ainda, para reuniões de pais e mestres. Internamente, os galpões retangulares eram repartidos em quatro salas, divididas por tábuas grossas e largas utilizadas como quadro de giz e quadro mural e, também, como divisórias entre as salas; não atingiam o teto, nem o solo, não tinham o objetivo de fechar as classes, pois, como dissemos antes, os galpões não possuíam paredes laterais. Era uma escola literalmente aberta, fechada apenas no teto pela cobertura de palha. Construção de alvenaria, só existia uma sala onde funcionava a diretoria, secretaria, almoxarifado, entre outros, e os sanitários. (GOÉS, 1980). Todos os Acampamentos eram dotados da mesma infraestrutura. As aulas aconteciam em horários regulares, nos três turnos, de forma idêntica à educação da rede de ensino pública. À noite funcionava como escola para educação de adultos.

Os professores que participavam desse experimento recebiam formação variada, parte era constituída por voluntários, da comunidade, e parte por funcionários da prefeitura. De início, os professores foram capacitados em cursos emergenciais; até 1962, a prefeitura realizou dois desses cursos: do primeiro, em 1961, participaram 250 candidatos que foram admitidos na Campanha como professores leigos; no segundo, como se apresentou um grande número de pessoas, houve uma seleção prévia, com a exigência de primário completo ${ }^{2}$ aos candidatos; 300 pessoas frequentaram o curso, que teve a duração de dois meses, mas só 250 foram aproveitadas na Campanha como monitoras, ou professoras leigas. Esse curso deu uma ênfase maior às três primeiras séries de ensino, denominadas de curso primário, campo de maior atuação da Campanha.

2 Primário completo é o equivalente, hoje, às cinco primeiras séries do ensino 
Apresentamos uma imagem dos Acampamentos e de uma sala de aula, construídos com material extraído de palhas de coqueiros, sem a presença dos tradicionais materiais de construção. 0 chão, como dissemos acima, era composto de barro batido e a criança está na escola sem usar sapatos, literalmente ela está com os pés no chão.

\section{IMAGEM 01}

\section{Sala de aula}

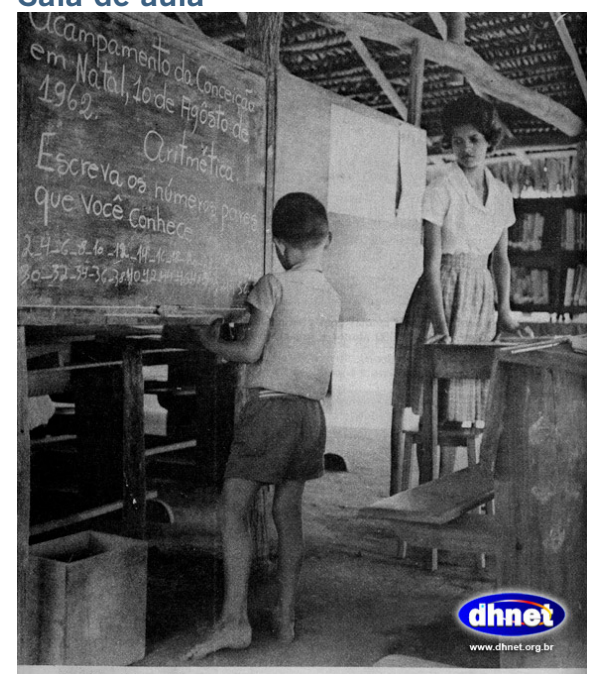

IMAGEM 02

Acampamento de no chão também se aprende a ler

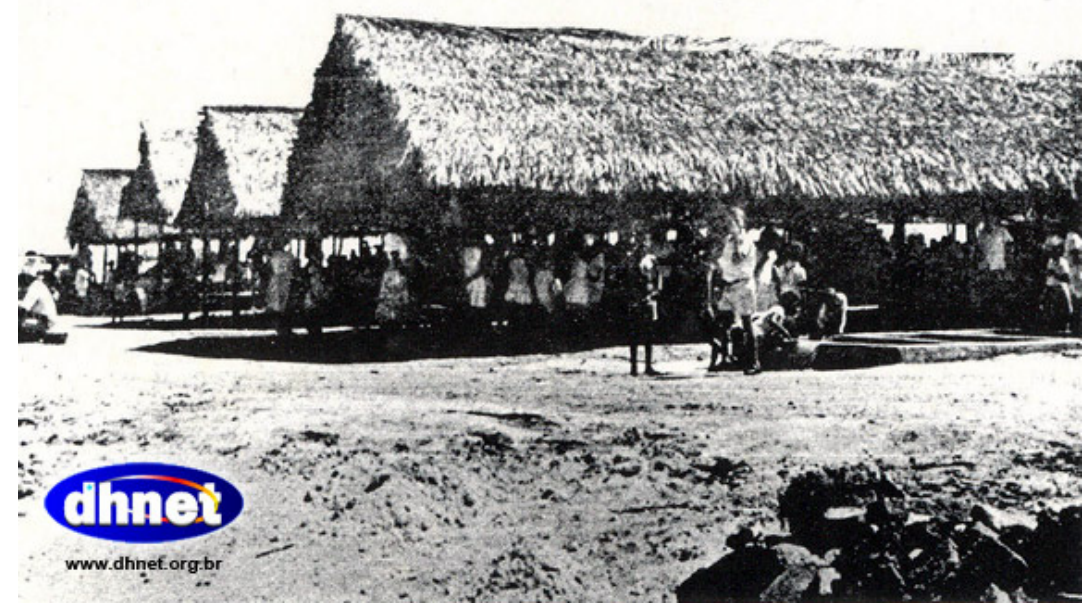

Imagens cedidas pela DHNET 
Com a ampliação da matrícula de alunos, surgiu a necessidade de um maior número de professores, com melhor qualificação, foi, então, criado o Centro de Formação de Professores (CFP), em 1962, instituição que passou a ser responsável pela coordenação pedagógica da Campanha, ou como relata Goés, o Centro de Formação de Professores tornou-se o "cérebro da Campanha" (1980, p.72). Oferecia três modalidades de curso:

a) Cursos de Emergência, para capacitação dos professores leigos, com duração de três ou quatro meses, para atender os municípios do interior que tinham convênio com a prefeitura de Natal;

b) Ginásio Normal, com duração de quatro anos, que atendia aos professores da Campanha que antes haviam frequentado os Cursos de Emergência;

c) e o Colégio Normal, de nível colegial, aperfeiçoando a formação dos professores da Campanha, sendo também aberto para outras pessoas interessadas.

O Centro de Formação deu maior dinamismo e organicidade à Campanha. Além dos cursos de formação de professores, foi também responsável pela supervisão e por toda a orientação técnico-pedagógica, que era realizada semanalmente por meio de reuniões e visitas semanais. Possuía, ainda, um Centro de Recursos Audio-Visuais, que preparava material didático-pedagógico, e uma Escola de Demonstração, que servia de laboratório para professoras e alunas do CFP.

O material didático-pedagógico utilizado na Campanha foi bastante diversificado. No início, o processo de ensino-aprendizagem não diferia do que existia na rede de ensino público, pouco a pouco, com o amadurecimento da Campanha, o processo de ensino foi sendo renovado, modificado. Muito utilizado foi o "Livro de Leitura 'De Pé no Chão Também se Aprende a Ler", adaptação do "Livro de Leitura para Adultos do Movimento de Cultura Popular do Recife" 3 , como está escrito na folha de rosto do livro, ou como diz o Secretário de Educação à época, Moacyr de Goés, na apresentação do livro:

Este "Livro de Leitura para Adultos da Campanha de Pé no Chão Também se Aprende a Ler" não é um trabalho original, é uma adaptação, às condições locais do Rio G. do Norte do "Livro de Leitura para Adultos do Movimento de Cultura Popular do Recife". Se a "Cartilha" do MCP é válida, como acreditamos, então, o certo é que aproveitemos esta experiência válida e apliquemo-la entre nós. (1963)

3 Recife, capital do Estado de Pernambuco; estado situado no Nordeste brasileiro, próximo ao Rio Grande do Norte. 
Havia grande integração entre o movimento educacional de Natal, com o de Recife. Miguel Arraes, governador do estado de Pernambuco e Djalma Maranhão, prefeito de Natal, estavam muito próximos politicamente, comungavam das mesmas lutas e ideais. Esse livro de leitura contém um conteúdo bastante crítico, conscientizador e também de valorização da cultura popular em suas múltiplas interpretações. Algumas das lições são bastante esclarecedoras da forma como eram utilizadas essas expressões, a exemplo de:

É preciso que se forme, no Brasil, uma ampla frente, congregando todos que trabalham para suprimir as causas da miséria do povo. 0 sofrimento do nosso povo é apenas uma consequência. As causas que geram esses sofrimentos, são mais profundas. Só podem ser eliminadas com planificação e reforma de base. (p.35)

$\mathrm{Ou}$,

O folclore é o conjunto das tradições de um povo. As mais populares danças do Nordeste são: quadrilha, araruna, bambelô, chegança, bumba-meu-boi e pastoril. (p.34)

O uso da cultura popular, nas mais diversas expressões, se fez presente em todos os momentos. O galpão de forma circular, que todo Acampamento possuía, foi palco de demonstrações artísticas variadas, inclusive, as apresentações folclóricas de cada bairro eram bastante exploradas: no bairro das Rocas, a "Sociedade Araruna de Danças Antigas"; no bairro da Conceição, o "Bambelô Asa Branca"; no bairro do Carrasco, os "Congos" e o "Boi Calemba", entre outros.

\section{Como diz Germano,}

[...] é importante que se diga, desde logo, que a Campanha significou, além das escolinhas e dos Acampamentos Escolares, a criação de bibliotecas populares, de praças de cultura, do Centro de Formação de Professores, do Teatrinho do Povo, da Galeria de Arte; significou a formação de círculos de leitura, a realização de encontros culturais, a reativação de grupos de danças folclóricas, a promoção de exposição de arte, a apresentação de peças teatrais, isto é, redundou numa organização cultural da cidade, onde o povo participava efetivamente e não apenas assistia como mero espectador. (1982, p.102,103)

O movimento da Campanha de Pé no Chão Também se Aprende a Ler representou uma modificação geral na cultura da cidade. A Campanha extrapolou os limites tradicionais de ação das nossas escolas, mobilizou toda a cidade, a cultura popular recebeu um grande incentivo e valorização, grupos folclóricos que estavam desaparecendo ressurgiram e, principalmente, as camadas mais pobres da população iniciaram um processo de apreensão e 
domínio do saber culto, até então tão distante. Assim como o MEB, essa foi outra experiência em educação popular desbaratada pelo golpe de Estado de 1964.

\section{CONSIDERAÇÕES FINAIS}

Essa experiência educacional estudada é um dos representantes dos movimentos sociais populares, de tendência nacionalista, com propostas de reformas sociais que, se não tivessem sido ceifadas em 1964, poderiam avançar mais em suas realizações. Foram movimentos liderados por intelectuais das camadas médias, católicos e não católicos, socialistas e não socialistas. Apresentam um aspecto romântico, muitas vezes atribuindo à educação um papel equivocado de transformação, resquícios da crença iluminista nas potencialidades regeneradoras da educação (Beisiegel, 2004), mas também representaram momentos de libertação, de busca progressiva por uma sociedade mais justa e humanitária.

\section{REFERÊNCIAS}

Beisiegel, C. R. (2004). Estado \& educação popular. Brasília: Líber Livro Editora.

Germano, J. W. (1982). Lendo e aprendendo: a Campanha de Pé no Chão. São Paulo: Autores Associados: Cortez.

Germano, J. W. (2004). Afinidades românticas da educação popular. In: XI Encontro de Ciências Sociais. Anais...Aracaju,SE. CISO Norte-Nordeste.

Goés, Moacyr. (1980). De Pé no Chão Também se Aprende a Ler (1961-1964) - uma escola democrática. Rio de Janeiro: Editora Civilização Brasileira S.A.

Le Goff, J. (1996). História e Memória. Campinas,SP : Editora da UNICAMP.

De Pé no Chão Também Se Aprende a Ler. Livro de Leitura.(2015) Brasília: Gabinete da Senadora Fátima Bezerra.

Paiva, M. M. (Org.). (2009) Escolas Radiofônicas de Natal: uma história construída por muitos (1958 - 1966). Brasília: Líber Livro Editora. 